Burry, A. F. (1970). Paper presented to the Heberden Society.

Burry, A. F. (1971). In Renal Infection and Renal Scarring, ed. P. KincaidSmith and K. F. Fairley, p. 335. Melbourne, Mercedes.

Calder, I. C., Funder, C. C., Green, C. R., Ham, K. N., and Tange, J. D. (1971). British Medical fournal, 4, 518 .

Calder, I. C., Funder, C. C., Green, C. R., Ham, K. N., and Tange, J. D. (1972). British Medical fournal, 1, 152.

Clarkson, A. R., and Lawrence, J. R. (1971). In Renal Infection and Renal Scarring, ed. P. Kincaid-Smith and K. F. Fairley, p. 375. Melbourne, Mercedes.

Clausen, E., and Pedersen, J. (1961). Acta Medica Scandinavica, 170, 631.

Cove-Smith, J. R., and Knapp, M. S. (1973). Lancet, 2, 70.

Dubach, U. C. (1971). Deutsche Medizinische Wochenschrift, 96, 303.

Gault, M. H. (1972). Canadian Medical Association fournal, 107, 756.

Gault, M. H., Blennerhassett, J., and Muehrcke, R. C. (1971). American fournal of Medicine, 51, 740.

Gault, M. H., Rudwal, T. C., Engles, D. W., and Dossetor, J. B. (1968). Annals of Internal Medicine, 68, 906.

Gilman, A. (1964). American fournal of Medicine, 36, 167.

Hart, F. D., Taylor, R. T., Huskisson, E. C., and Shenfield, G. M. (1970). British Medical fournal, 4, 363.

Harvald, B. (1963). American fournal of Medicine, 35, 481.

Kincaid-Smith, P. (1970 a). British Medical fournal, 4, 618

Kincaid-Smith, P. (1970 b). Prescribers' fournal, 10, 8.

Kincaid-Smith, P., Nanra, R. S., and Fairley, K. F. (1971). In Renal Infection and Renal Scarring, ed. P. Kincaid-Smith and K. F. Fairley, p. 385. Melbourne, Mercedes.

Kingsiey, D. P. E., et al. (1972). British Medical Fournal, 4, 656.

Koutsaimanis, K. G., and de Wardener, H. E. (1970). British Medical Fournal, 4, 131.

Lawson, A. A. H., and MacLean, N. (1966). Annals of the Rheumatic Diseases, 25,441 .

Lawson, D. H. (1973). Fournal of Chronic Diseases, 26, 39.

Linton, A. L. (1972). Canadian Medical Association fournal, 107, 749.

Little, P. J. (1962). Lancet, 1, 1149.
Murray, R. M. (1972 a). British Medical fournal, 4, 131.

Murray, R. M. (1972 b). Scottish Medical fournal, 17, 393.

Murray, R. M., Lawson, D. H., and Linton, A. L. (1971). British Medical Fournal, $1,479$.

Murray, R. M., and Smith, R. (1972). Lancet, 1, 73.

Nanra, R. S., and Kincaid-Smith, P. (1970). British Medical fournal, 3, 559.

Nanra, R. S., Chirawong, P., and Kincaid-Smith, P. (1971). In Renal Infection and Renal Scarring, ed. P. Kincaid-Smith and K. F. Fairley, p. 347. Melbourne, Mercedes.

Nanra, R. S., et al. (1970). Medical fournal of Australia, 1, 293.

Nordenfelt, O. (1972). Acta Medica Scandinavica, 191, 11 .

Olaffson, O., Gudmundsson, K. R., and Brekkan, A. (1966). Acta Medica Scandinavica, 179, 121 .

Prescott, L. F. (1969). Scottish Medical fournal, 14, 82.

Prescott, L. F. (1970). British Medical fournal, 4, 493.

Prescott, L. F. (1971). In Renal Infection and Renal Scarring, ed. P. KincaidSmith and K. F. Fairley, p. 421. Melbourne, Mercedes.

Raaflaub, J., and Dubach, U. C. (1969). Klinische Wochenschrift, 47, 1286.

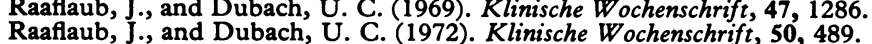

Ropes, M. W., Bennett, G. A., Cobb, S., Jacox, R., and Jessar, R. A. (1959). Bulletin of the Rheumatic Diseases, $9,175$.

Saker, B. M., and Kincaid-Smith, P. (1969). British Medical fournal, 1, 161.

Sanerkin, N. G. (1971). British Medical Fournal, 2, 223.

Scott, J. T. (1966). American Heart fournal, 71, 715.

Shelley, J. H. (1967). Clinical Pharmacology and Therapeutics, 8, 427.

Sórensen, A. W. S. (1966). Nephron, 3, 366.

Spühler, O., and Zollinger, H. U. (1953). Zeitzschrift für klinische Medizin, 151,1 .

de Wardener, H. E., and Koutsaimanis, K. G. (1971). British Medical Fournal, 2, 45 .

Waters, W. E., Elwood, P. C., and Asscher, A. W. (1973). Lancet, 1, 341.

Wesson, L. G. (1969). Physiology of the Human Kidney, p. 97. New York, Grune and Stratton.

Wigley, R. D. (1971). New Zealand Medical fournal, 74, 301.

Wilson, D. R. (1972). Canadian Medical Association fournal, 107, 752.

\title{
Ventilation-Perfusion Lung Scanning for Pulmonary Emboli
}

\author{
OLWEN WILLIAMS, JAMES LYALL, MARIAN VERNON, D. N. CROFT
}

British Medical Fournal, 1974, 1, 600-602

\section{Summary}

The conventional method of lung scanning detects defects of pulmonary artery perfusion. False positive results occur because regions of hypoventilation, such as are present in obstructive airways disease, also cause defects of perfusion. The converse is not true, however, as defects of perfusion continue to be ventilated. Thus in pulmonary embolism ventilation-perfusion discrepancy (normal ventilation and impaired perfusion) occurs.

We have assessed the clinical value of this discrepancy. Out of 18 patients with ventilation-perfusion discrepancy 14 had a final diagnosis of pulmonary emboli, whereas in none of the 34 patients without the discrepancy was this final diagnosis made. We conclude that combined ventilationperfusion lung scanning distinguishes pulmonary emboli from other lung conditions such as asthma and bronchitis which cause impaired pulmonary perfusion. The false positive rate was only $4 \%$ overall and $7.7 \%$ in patients with perfusion defects.

\section{Introduction}

Lung perfusion scanning is of value in the diagnosis of pulmonary embolism and is a simple and safe screening proced-

Isotope Department, St. Thomas's Hospital, London SE1 7EH OLWEN WILLIAMS, M.sC., M.R.C.P., Senior Medical Registrar JAMES LYALL, M.SC., M.R.C.P., Lecturer in Medicine

MARIAN VERNON, B.SC., Physicist

D. N. CROFT, D.M., M.R.C.P., Consultant Physician ure. Interpretation of lung scans, however, creates a problem in some patients because abnormal perfusion is not peculiar to pulmonary embolism but can appear in a variety of lung diseases, including bronchitis and asthma (Lopez-Majano et al., 1966; Mishkin and Wagner, 1968). There is a need for a reliable method of diagnosing emboli in patients with asthma, bronchitis, and other conditions with impaired pulmonary perfusion.

Animal studies show that a reduction in lung ventilation such as occurs in man with chronic obstructive airways diseases leads rapidly to a corresponding reduction in lung perfusion. On the other hand, reduction in lung perfusion, as in pulmonary embolism, does not lead to a correspondingly marked and sustained reduction in ventilation. With this in mind several workers have suggested that combined ventilation-perfusion lung scans might aid more specific diagnosis of pulmonary embolism (De Nando et al., 1970; Farmelant and Trainor, 1971). Their studies were made on a total of 57 patients and the results justified a clinical trial with a larger series. We have therefore performed 100 combined ventilation-perfusion lung scans on patients with pulmonary problems and have assessed the results in relation to the final diagnosis.

\section{Patients and Methods}

The patients had been routinely referred by clinicians in the hospital. Both scans were performed at the same session, ventilation scanning always preceding perfusion scanning. The combined scans took 20 minutes. Perfusion images were obtained by using macroaggregated albumin (MAA) labelled with ${ }^{99 \mathrm{~m}} \mathrm{Tc}$. Gaseous ${ }^{133} \mathrm{Xe}$ was used for ventilation imaging. All the images were recorded on Polaroid film by means of a Nuclear Enterprises mark III gamma camera with a diverg- 
ing collimator. The collimator was designed for use with ${ }^{133} \mathrm{Xe}$ and ${ }^{99} \mathrm{~m} \mathrm{Tc}$ and was made at St. Thomas's Hospital (Ahmad and Clapham, 1974). The aim was to produce an overall resolution of $3.5 \mathrm{~cm}$ at a distance of $10 \mathrm{~cm}$ from the collimator face, together with adequate sensitivity, and to include both lungs in the field of view.

The patient was seated with his back to the camera and shown how to breathe from a closed-circuit spirometer via a facemask. After acclimatization and at full expiration 3-5 $\mathrm{mCi}$ of ${ }^{133} \mathrm{Xe}$ was injected through the tubing connecting spirometer to mask. A picture was then taken with the breath held after a full inspiration. After rebreathing until the count rate over the lungs was steady an equilibrium picture was taken. The spirometer was removed and washout pictures were taken while an extractor system removed the exhaled ${ }^{133} \mathrm{Xe}$. Immediately after this $1 \mathrm{mCi}$ of ${ }^{99 \mathrm{mTC}} \mathrm{MAA}$ was slowly injected intravenously with the patient supine and breathing slowly and deeply. Anterior, posterior, and lateral images were then recorded with the patient sitting.

The radiation dose for ${ }^{98 \mathrm{~m}} \mathrm{Tc}$ perfusion scans was $0.19 \mathrm{rem}$ to the lungs, and for ${ }^{1 / 3} \mathrm{e}$ ventilation scans $0.5-1.0 \mathrm{rem}$ to the bronchus. The skin dose for a single chest $x$-ray exposure is 0.15 rem and for pulmonary angiography $13.2 \mathrm{rem}$ (Trott et al., 1970).

The ventilation scan was regarded as normal if there was uniform distribution of radioactivity throughout the lung fields in both single-breath and equilibrium pictures and neither localized nor generalized retention of ${ }^{133} \mathrm{Xe}$ beyond three minutes during washout (Medina et al., 1969). For each combined study a visual assessment was made of whether there was a defeot of perfusion. If a defect existed the image was compared with the ventilation image. A visual assessment was then made to decide whether the abnormality of perfusion was greater than that of ventilation. If this was the case ventilation-perfusion discrepancy existed.

The ventilation-perfusion lung scan results were compared with the final diagnosis in each patient. This diagnosis was determined by independent clinicians who had available to them all the data on the patient except the ventilation scans. The data included history and results of examination, chest $x$-ray appearances, electrocardiogram, blood count and biochemical values, ${ }^{125}$ I fibrinogen uptake, ultrasound dopplegram, ascending phlebograms of the legs, and perfusion lung scans. Finally, these clinicians considered the response to treatment and clinical outcome of the illness. We believe that a diagnosis of pulmonary embolism should not be based on any one procedure and that a diagnosis based on compound evidence is the most accurate at present available.

\section{Results}

Of the 100 combination scans analysed 48 showed normal perfusion and 52 abnormal perfusion. The 48 patients with normal perfusion also had a normal ventilation scan. Of the 52 patients with abnormal perfusion 34 had coinciding abnormalities of ventilation with no ventilation-perfusion discrepancy (see table). In 18 ventilation did not match perfusion and in all these cases the perfusion defect exceeded the ventilation defect. None of the patients without ventilationperfusion discrepancy had a final clinical diagnosis of pulmonary embolism but of the 18 patients in whom this discrepancy was present 14 had a final diagnosis of pulmonary embolism.

In four of the patients with a final diagnosis other than of pulmonary embolism the scan pattern of embolism oocurred, giving a false positive rate of $7.7 \%$ in patients with perfusion defects. Two of the four false-positives occurred in patients with postoperative pneumonia, in whom pulmonary embolism was an alternative diagnosis. An example of ventilationperfusion discrepancy is shown in the fig.
Results of Combination Ventilation-Perfusion Scanning in the 52 Patients who had Abnormal Perfusion Scans

\begin{tabular}{|c|c|c|}
\hline & Final Diagnosis & $\begin{array}{l}\text { No. of } \\
\text { Patients }\end{array}$ \\
\hline Ventilation-perfusion discrepancy & $\begin{array}{l}\text { Pulmonary emboli } \\
\text { Fibrotic sarcoid } \\
\text { Postoperative pneumonia }\end{array}$ & $\begin{array}{r}14 \\
2 \\
2\end{array}$ \\
\hline Total & & 18 \\
\hline No ventilation-perfusion discrepancy & $\begin{array}{l}\text { Pulmonary emboli } \\
\text { Cardiac failure } \\
\text { Pneumonia } \\
\text { Tuberculosis } \\
\text { Fmphysema } \\
\text { Chronic bronchitis } \\
\text { Asthma } \\
\text { Pleurisy } \\
\text { Pleural thickening }\end{array}$ & $\begin{array}{r}0 \\
6 \\
10 \\
6 \\
5 \\
2 \\
1 \\
2 \\
2\end{array}$ \\
\hline Total & & 34 \\
\hline
\end{tabular}

\section{Discussion}

Most lung perfusion scans are done to exclude or confirm
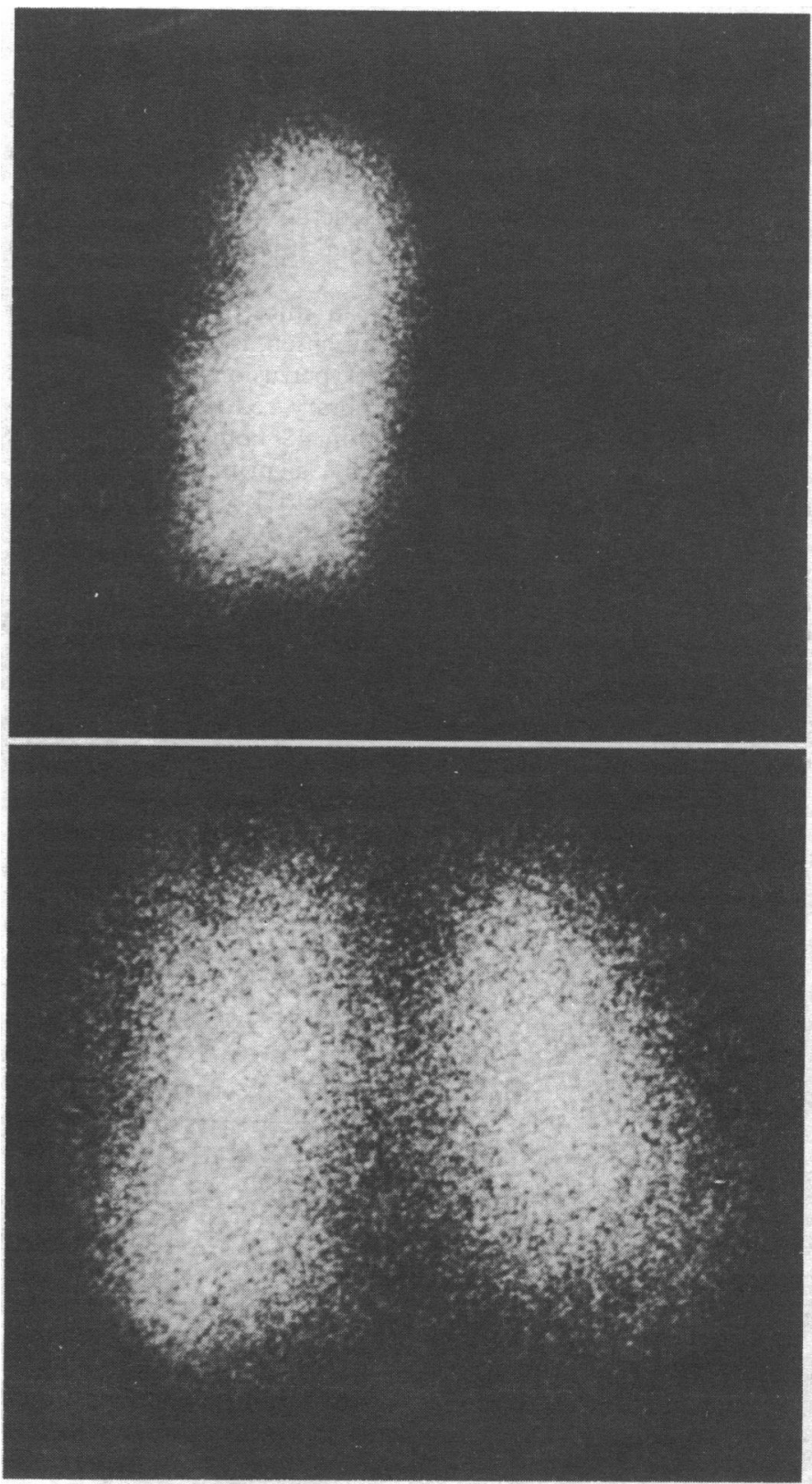

Posterior views of combined ventilation-perfusion lung scan from patient suspected of having had pulmonary embolus. Top: Lung perfusion scan showing normal perfusion on left and absence of perfusion on right. Bottom:
Normal lung ventilation scan. 
a diagnosis of pulmonary embolism. This has always been a notoriously difficult diagnosis to substantiate as emboli may occur silently or may mimic pneumonia, pleurisy, myocardial infarotion, or cor pulmonale. The problem of basing a diagnosis of pulmonary embolism on clinical findings alone was illustrated by a series of 71 patients in whom embolism was suspected and who all had pulmonary angiograms. Even with the help of simple investigations (electrocardiography, $x$-ray examination, and biochemical tests) it was impossible to predict the presence or absence of emboli (Poulouse et al., 1970). With lung perfusion scanning it is usually possible to make a correct diagnosis in patients with a normal chest $x$-ray picture and no obstructive airways disease.

In studies where emboli were shown by angiography the incidence of false negative perfusion scans was 3.7\% (Fred et al., 1966) or nil (Poulouse et al., 1970; Szucs et al., 1971). With experimentally induced emboli in dogs the overall false negative rate was $17 \%$, the emboli being missed either because they involved very small areas of lung or because they lodged centrally, causing only partial obstruction to flow (Moser et al. 1969). This has not yet been confirmed in man.

For clinical purposes a normal perfusion scan excludes a pulmonary embolus. The converse is far from true, as other lung disease can cause alteration of pulmonary perfusion. Clinically these conditions (pneumonia, effusion, etc.) are often apparent on the chest $x$-ray film. Abnormal perfusion associated with normal chest $x$-ray appearances, however, may also be found in chronic obstruotive airways disease and asthma. It is in this group that an improved technique is required.

Reduction in ventilation causes an immediate reduction in perfusion which persists while ventilation is impaired (Isawa et al., 1971). On the other hand, if perfusion is impaired, as in embolism, there is only a temporary reduction of ventilation, which returns to normal within 48 hours (Wolfe et al., 1966; Iswa et al., 1972). Clinically a primary disturbance of ventilation, as in emphysema, should be accompanied by an equal and corresponding disturbance of perfusion. Pulmonary embolism would thus be expected to give rise to a discrepancy between the extent of perfusion and ventilation. Our data confirm in a clinical setting that the presence of ventilation-perfusion discrepancy is linked with pulmonary embolism and that the lack of this discrepancy is not.

Other workers have assessed ventilation-perfusion discrepancy in the diagnosis of embolism. De Nardo found that in 10 patients with emboli the embolic area was well ventilated but underperfused, while five patients with other conditions had equal impairment of ventilation and perfusion (De Nardo et al., 1970). Similar results have been obtained by others (Farmelant and Trainor, 1971). Review of the literature and of the cases reported here shows only seven out of 100 cases in which ventilation-perfusion discrepancy was found in the absence of embolism, which indicates that ventilation-perfusion discrepancy is a sensitive marker of pulmonary embolism.

Ventilation scanning appears to be relevant when the perfusion scan is abnormal and the patient has a history of obstructive airways disease, particularly where the chest $x$-ray picture either is normal or shows only minor abnormalities. Ventilation scanning is a quick, simple, and safe procedure which can be carried out in radioisotope departments equipped with a gamma camera. We have used this procedure routinely and in a study of the incidence of pulmonary emboli after surgery, as described in the succeeding paper (Browse et al., 1974).

Requests for reprints should be sent to Dr. D. N. Croft.

\section{References}

Ahmad, A. I., and Clapham, W. F. (1974). In preparation.

Browse, N. L., Clemenson, G., and Croft, D. N. (1974). British Medical fournal, 0, 000

De Nardo, G. L., Goodwin, D. A., Ravasini, R., and Deitrich, P. A. (1970). New England fournal of Medicine, 282, 1334.

Farmelant, M. H., and Trainor, J. C. (1971). fournal of Nuclear Medicine, $12,586$.

Fred, H. L., Burdine, J. A., Gonzalez, D. A., Lockhart, R. W., and Peabody,

C. A. (1966). New England fournal of Medicine, 275, 1025.
Isawa, T., Benfield, J. R., Johnson, D. E., and Taplin, G. V. (1971). Radiology, 99, 355 .

Isawa, T., Taplin, G. V., Beazell, J., and Criley, J. M. (1972). Radiology, $102,101$.

Lopez-Majano, V., Tow, D. E., and Wagner, H. N. (1966). Fournal of the American Medical Association, 197, 81.

Medina, J. R., Lillehei, J. P., Loken, M. K., and Ebert, P. V. (1969). fournal of the American Medical Association, 208, 985.

Mishkin, F. S., and Wagner, H. N. (1968). Fournal of the American Medical Association, 203, 1019.

Moser, K. M., et al. (1969). Circulation, 39, 663.

Poulouse, K. P., Reba, R. C., Gilday, D. L., Deland, F. H., and Wagner, H. N. (1970). British Medical fournal, 3, 67.

Szucs, M. M., et al. (1971). Annals of Internal Medicine, 74, 161.

Trott, N. G., Stacey, A. J., and Dermentzoglou, F. M. (1970). In A.E.C. Symposium Series 20. Medical Radionuclides, Radiation Dose and Effects, p. 157

Wolfe, W. G., Pircher, F. J., and Sabiston, D. C. (1966). Surgical Forum, $17,119$. 